Article

\title{
Shape-Memory Metallopolymer Networks Based on a Triazole-Pyridine Ligand
}

\author{
Josefine Meurer ${ }^{1,2}$, Julian Hniopek ${ }^{3,4,5}$ (D) Stefan Zechel ${ }^{1,2}$, Marcel Enke ${ }^{1,2}$, Jürgen Vitz ${ }^{1,2}$,

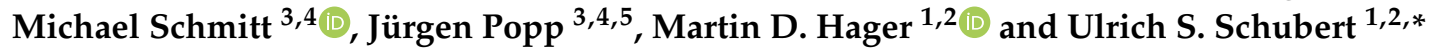 \\ 1 Laboratory of Organic and Macromolecular Chemistry (IOMC), Friedrich Schiller University Jena, \\ Humboldstr. 10, 07743 Jena, Germany; josefine.meurer@uni-jena.de (J.M.); stefan.zechel@uni-jena.de (S.Z.); \\ marcel.enke@uni-jena.de (M.E.); j.vitz@uni-jena.de (J.V.); martin.hager@uni-jena.de (M.D.H.) \\ 2 Jena Center of Soft Matter (JCSM), Friedrich Schiller University Jena, Philosophenweg 7, \\ 07743 Jena, Germany \\ 3 Institute of Physical Chemistry (IPC), Friedrich Schiller University Jena, Helmholzweg 4, 07743 Jena, \\ Germany; julian.hniopek@uni-jena.de (J.H.); m.schmitt@uni-jena.de (M.S.); juergen.popp@uni-jena.de (J.P.) \\ 4 Abbe Center of Photonics, Friedrich Schiller University Jena, Albert-Einstein-Straße 6, 07745 Jena, Germany \\ 5 Leibniz Institute of Photonic Technology, e. V. Jena, Albert-Einstein-Str. 9, 07745 Jena, Germany \\ * Correspondence: ulrich.schubert@uni-jena.de
}

Received: 30 September 2019; Accepted: 4 November 2019; Published: 15 November 2019

\begin{abstract}
Shape memory polymers represent an interesting class of stimuli-responsive polymers. With their ability to memorize and recover their original shape, they could be useful in almost every area of our daily life. We herein present the synthesis of shape-memory metallopolymers in which the switching unit is designed by using bis(pyridine-triazole) metal complexes. The polymer networks were synthesized via free radical polymerization of methyl-, ethyl- or butyl-methacrylate, tri(ethylene glycol) dimethacrylate and a methacrylate moiety of the triazole-pyridine ligand. By the addition of zinc(II) or cobalt(II) acetate it was possible to achieve metallopolymer networks featuring shape-memory abilities. The successful formation of the metal-ligand complex was proven by Fourier transform infrared (FT-IR) spectroscopy and by ${ }^{1} \mathrm{H}$ NMR spectroscopy. Furthermore, the shape-recovery behavior was studied in detailed fashion and even triple-shape memory behavior could be revealed.
\end{abstract}

Keywords: shape-memory polymer; metallopolymer; triazole-pyridine-metal complex; stimuli responsive polymer

\section{Introduction}

Smart materials, in particular smart polymers, gain more and more importance nowadays. These materials are able to change their functions/properties for a predetermined propose after they sensed their own state and/or the environment [1-3]. A large variety of polymers is currently known to feature such stimuli-responsive and therefore also smart behavior [4]. Such polymers change their properties during the application of an external trigger [5,6]. Possible triggers are, for example, temperature [7-9], pH-value [10,11], light [12,13], electric field [14] and many more [15]. The stimuli-responsive behavior is a precondition for a wide range of different applications such as self-healing behavior [16] or sensor functions and a variety of different properties can be switched, e.g., optical properties [17].

One very important class of smart polymers are shape-memory polymers [18]. These materials have the ability to memorize their original shape (i.e., permanent shape). They can be deformed under certain conditions resulting in one or more new form(s) (i.e., temporary shape(s)), which can be fixed. An external trigger leads to the recovery of the memorized original shape [19-23]. 
The shape-memory effect was firstly found for shape-memory alloys. In 1963, this ability was obtained for a Ti-Ni alloy [24]. However, polymers were investigated in a more detailed fashion and many different possibilities for shape-memory polymers could be revealed such as light-triggered shape recovery [25].

Shape-memory polymers represent promising materials for numerous potential applications. For instance, they can be utilized in commercial materials, e.g., in textiles or plastic screws [26], for self-healing materials utilizing the so-called shape-memory assisted self-healing (SMASH), which promotes the healing process [27,28], for biomedical applications, e.g., for minimal invasive surgery [29], and in particular in the area of aerospace (e.g., self-deploying antennas) where size are always crucial parameters [30]. For that reason, the latest research on this topic is very versatile. For example, Wang et al. presented a pre-strained 2D shape-memory polymer system, which could be switched to a freestanding 3D architecture [31]. Other groups focused their work on biocompatible SMP foams as new vascular materials for drug-release [32]. Also, new water-responsible polymers were investigated for biomedical applications [33].

The ability for shape-recovery is not particularly based on one specific property of the polymer. It results from the structure as well as the morphology of the whole polymeric system [20]. Thus, shape-memory polymers need at least two different structural units: a stable network, which is responsible for the stability of the whole polymer and determines the permanent shape and a reversible phase enabling the shape-switching. The deformation of the permanent phase is the reason for the shape recovery and, thus, the driving force for the shape-memory behavior. This stable part of the polymer can be generated in three different ways: It is possible to utilize either i) chemical (covalent) [34] or ii) physical (supramolecular) [35] crosslinking; however, iii) interpenetrating networks can also act as the stable network [36]. The second subunit, which is required for shape-memory polymers, must be addressable. This means the second phase is reversible and can be influenced by an external stimulus. This switchable moiety is responsible for the fixation of the temporary shape of the polymer as well as for the possibility to switch between the different shapes [37]. In general, there are many possibilities to design such phase. Possible options include the switching via crystallization/melting [34,38-40], transition between different liquid crystalline phases [41], glass transition [42,43], reversible covalent bonds [25,44] and supramolecular interactions [45-47]. One example for supramolecular bonds in shape-memory polymers are metal ligand interactions, e.g., utilizing 4-oxy-2,6-bis( $N$-methylbenzimidazolyl)pyridine and an europium salt [46], triphenylphosphine units, which were crosslinked by the addition of rhodium salts [48] or a terpyridine ligand which formed complexes with nickel and iron salts [49]. The latter one represents a rarely studied system even though it features a lot of potential in the context of shape-memory materials. The metal-ligand interactions can be addressed in polymers using a variety of different stimuli and can be fine-tuned according to the strength of the supramolecular unit [50]. Therefore, the different phases of the polymeric systems can be adjusted to the function. However, metallopolymers were rarely investigated in respect to a shape-recovery behavior and general design principles are currently still missing.

Therefore, the current study focuses on the design of shape-memory metallopolymers and the elucidation of structure-property relationships. For this purpose, the temporary shape should be fixed via reversible metal ligand interactions. As ligand for the current system, a triazole-pyridine was chosen, which has not been used, as far as we know, in shape-memory metallopolymers. Furthermore, different methacrylates and a dimethacrylate (tri(ethylene glycol) dimethacrylate) as permanent crosslinker were utilized for the polymer synthesis (Figure 1). Additionally, these polymer networks also featured the pyridine-triazole ligands for the fixation of the temporary shape by the reversible formation of complexes with either zinc(II) or cobalt(II) acetate. The binding behavior of the metals to the ligands was studied using isothermal titration calorimetry (ITC) as well as spectroscopic methods like IR or Raman spectroscopy. Finally, the shape-memory behavior was investigated in detail and even triple-shape memory behavior could be obtained. The main goal of our work was to investigate the 
shape-memory process and to elucidate structure-property-relationships of our new metallopolymer networks based on a bis(triazole-pyridine) metal complex.

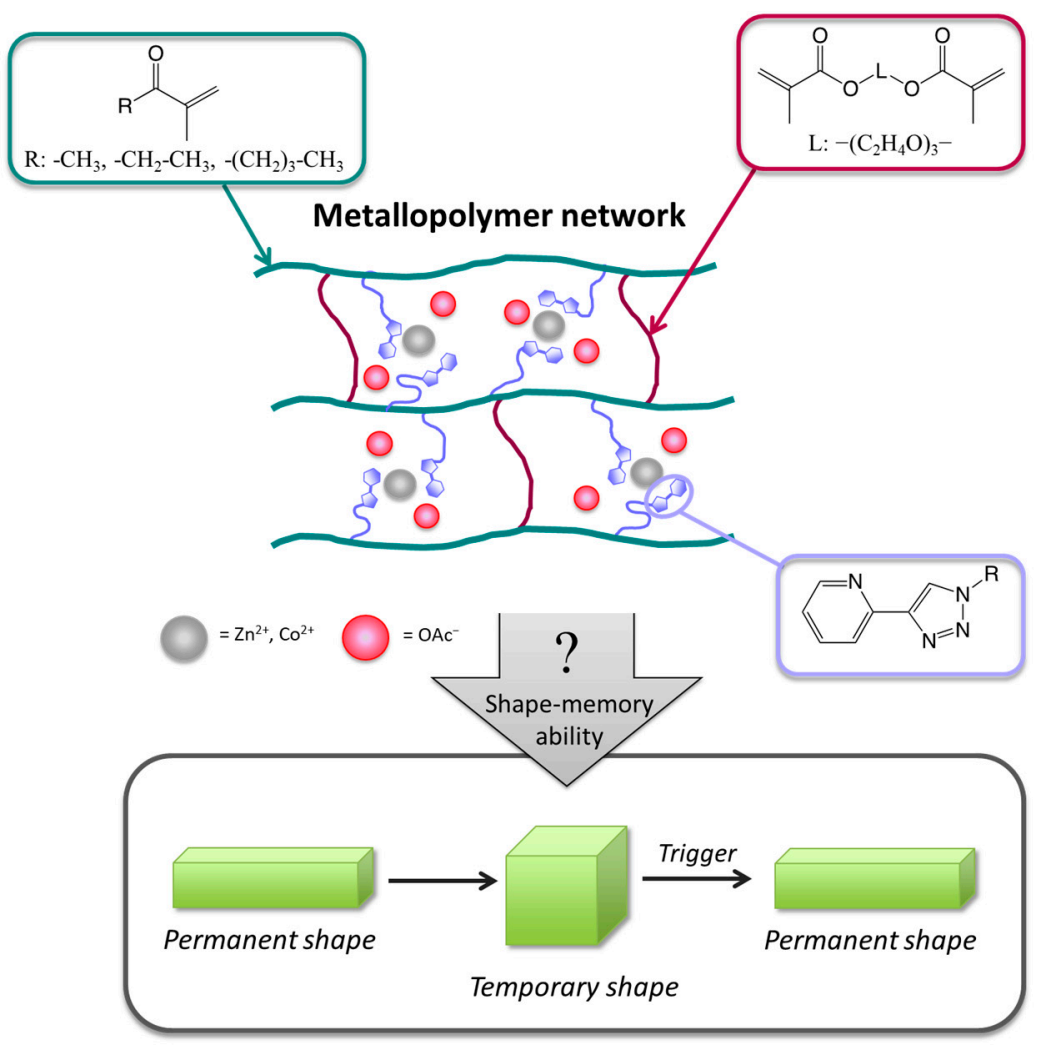

Figure 1. Schematic representation of the concept. Synthesis of metallopolymer networks, starting from different methacrylates (methyl-methacrylate (MMA), ethyl-methacrylate (EMA) and butyl-methacrylate (BMA)), tri(ethylene glycole) dimethacrylate, the synthesized ligand monomer and metal salts (zinc(II) or cobalt(II) acetate) enabling a shape-memory effect of the resulting dual networks.

\section{Experimental Part}

\subsection{Materials and Methods}

All chemicals were used as received from TCI (Eschborn, Germany), Sigma Aldrich (Darmstadt, Germany), Alfa Aesar (Kandel, Germany), Thermo Fisher Scientific (Geel, Belgium) and Acros Organics (Geel, Belgium) if not otherwise stated. All solvents were dried over molecular sieve under nitrogen atmosphere. The used liquid monomers, methyl-methacrylate, ethyl-methacrylate, butyl-methacrylate, and tri(ethylene glycol) dimethacrylate, were destabilized over a short AlOx column (neutral AlOx, obtained from Molecula, Darlington, UK).

Differential scanning calorimetry (DSC) was measured on a Netzsch DSC 204 F1 Phoenix instrument (Selb, Germany) under a nitrogen atmosphere with a heating rate of 10 and $20 \mathrm{~K} \mathrm{~min}^{-1}$. The thermogravimetric analysis (TGA) was carried under normal atmosphere using a Netzsch TG 209 F1 Iris (Selb, Germany).

Nuclear magnetic resonance spectra were measured using a Bruker AC $250(250 \mathrm{MHz})$, Bruker AC $300(300 \mathrm{MHz})$, Bruker AC $400(400 \mathrm{MHz})$ and a Bruker AC $600(600 \mathrm{MHz})$ spectrometers at $298 \mathrm{~K}$ (Billerica, MA, USA) if not stated differently. The chemical shift is given in parts per million (ppm on $\delta$ Scale) related to deuterated solvent.

Elemental analysis was performed utilizing a Vario El III (Elementar, Langenselbold, Germany).

FT-Raman spectra were recorded up to $4000 \mathrm{~cm}^{-1}$ with a spectral resolution of $4 \mathrm{~cm}^{-1}$ using a commercial Bruker MultiSpec spectrometer (Billerica, MA, United States). The Raman excitation light 
at $1064 \mathrm{~nm}$ was provided by a Nd:YAG laser (Klastech DeniCAFC-LC-3/40, Dortmund, Germany). The laser power at the samples was $1000 \mathrm{~mW}$. The FT-Raman spectra were recorded using the software package OPUS 6.5. To analyze the temperature-dependent behavior of P12-Zn, temperature-dependent Raman spectra were recorded. The samples were heated via temperature controlled stage LTS 350 (Linkam Scientific, Tadworth, United Kingdom) with a heating rate of $1^{\circ} \mathrm{C} / \mathrm{min}$. Five Raman spectra were recorded at $27^{\circ} \mathrm{C}$ before the heating to $150{ }^{\circ} \mathrm{C}$ was started. A Raman spectrum consisting of 32 single scans was recorded every minute during the heating process. The raw Raman spectra were pre-processed using $R$ (3.5.1). First the Raman spectra were restricted to the wavenumber region of interest, i.e., the region between 400 and $3200 \mathrm{~cm}^{-1}$. Subsequently, the Raman spectra were background-corrected using a SNIP algorithm (iterations $=50$, order $=2$, smoothing window $=3$ ) and normalized to the $\mathrm{CH}$-stretching area $\left(2800\right.$ to $\left.3100 \mathrm{~cm}^{-1}\right)$.

Fourier transform infrared (FT-IR) spectra were recorded from 600 up to $4000 \mathrm{~cm}^{-1}$ using an IR-Affinity 1 (Shimadzu, Kyōto, Japan).

The cyclo-mechanic-tests were performed on a MCR 301 rheometer from Anton Paar (Graz, Austria) using the convection oven device CTD 450, which covers a broad temperature range from -150 to $450{ }^{\circ} \mathrm{C}$. The samples were measured with a solid rectangular fixture setup (SRF12-SN13529, Anton Paar (Graz, Austria) in dimensions of approximately $29 \times 10 \mathrm{~mm}$ (length, width) and a thickness of approx. $1.5-3.5 \mathrm{~mm}$, the resulting sample gap was set to $15 \mathrm{~mm}$. After fixing the sample, the temperature was set to $90^{\circ} \mathrm{C}$ (respectively $110^{\circ} \mathrm{C}$ ). Subsequently, the sample was turned in a linear ramp $\left(10^{\circ} / \mathrm{min}\right)$ until a shear stress of $18000 \mathrm{~Pa}$ was reached. In the following cooling step down to $25^{\circ} \mathrm{C}\left(2{ }^{\circ} \mathrm{C} / \mathrm{min}\right)$, the shear stress of 18000 Pa was kept constant. Afterwards, the shear stress was reduced to $0 \mathrm{~Pa}$ with a rate of $20 \mathrm{~Pa} / \mathrm{s}$. Finally, the sample was again heated to the initial temperature of $90{ }^{\circ} \mathrm{C}$ (respectively $110{ }^{\circ} \mathrm{C} ; 2{ }^{\circ} \mathrm{C} / \mathrm{min}$ ). For operating the rheometer and analysis, the software RheoCompass ${ }^{\mathrm{TM}}$ V1.24.549-Release 64-bit (Anton Paar, Graz, Austria) was used and the obtained results were exported as csv-files and further processed with OriginPro 2018 (OriginLab Corporation, Northampton, MA, USA).

\subsection{Synthesis of the Monomer and Model System}

\subsubsection{1-[4-(Pyridine-2-yl)-1H-1,2,3-triazol-1-yl]undecane-1-ol (1)}

The synthesis was performed according to a literature procedure [51]. A suspension of 11-bromundecan-1-ol (1.406 g, $5.60 \mathrm{mmol})$, sodium azide $(390 \mathrm{mg}, 5.60 \mathrm{mmol})$, copper sulfate pentahydrate $(70 \mathrm{mg}, 0.28 \mathrm{mmol})$, sodium ascorbate $(278 \mathrm{mg}, 1.40 \mathrm{mmol})$ and 2-ethynyl pyridine (580 mg, $5.63 \mathrm{mmol})$ in a ethanol/water-mixture (V: 7:3, $15 \mathrm{~mL}$ ) was heated in the microwave to $125^{\circ} \mathrm{C}$ for $25 \mathrm{~min}$. Subsequently, a second addition of copper sulfate pentahydrate $(70 \mathrm{mg}, 0.28 \mathrm{mmol})$ occurred and the solution additionally was heated for $25 \mathrm{~min}$ at $125{ }^{\circ} \mathrm{C}$ in the microwave. A gel filtration (silica, ethyl acetate) provided the crude product as yellow solid, which was dissolved in dichloromethane. Precipitation from pentane yields 1 as withe powder $(1.423 \mathrm{~g}, 80 \%)$.

${ }^{1} \mathrm{H}$ NMR $\left(400 \mathrm{MHz}, \mathrm{CDCl}_{3}, \delta\right): 1.11-1.43\left(\mathrm{~m}, 14 \mathrm{H}, \mathrm{CH}_{2}\right), 1.47-1.67\left(\mathrm{~m}, 2 \mathrm{H}, \mathrm{O}-\mathrm{CH}_{2}-\mathrm{CH}_{2}\right), 1.78-2.05$ $\left(\mathrm{m}, 3 \mathrm{H}, \mathrm{N}-\mathrm{CH}_{2}-\mathrm{CH}_{2}, \mathrm{OH}\right), 3.64\left(\mathrm{t}, J=6.6 \mathrm{~Hz}, 2 \mathrm{H}, \mathrm{O}-\mathrm{CH}_{2}\right), 4.42\left(\mathrm{t}, J=7.1 \mathrm{~Hz}, 2 \mathrm{H}, \mathrm{N}-\mathrm{CH}_{2}\right), 7.24(\mathrm{dd}, J=$ 6.8, $5.3 \mathrm{~Hz}, 1 \mathrm{H}), 7.80(\mathrm{td}, J=7.8,1.6 \mathrm{~Hz}, 1 \mathrm{H}), 7.97-8.26(\mathrm{~m}, 2 \mathrm{H}), 8.58(\mathrm{~d}, J=4.4 \mathrm{~Hz}, 1 \mathrm{H}) \mathrm{ppm}$.

\subsubsection{1-(4-(Pyridine-2-yl)-1H-1,2,3-triazol-1-yl)undecanyl-methacrylate (2)}

The synthesis was performed under inert conditions and according to a literature report [52]. The 11-(4-(pyridin-2-yl)-1H-1,2,3-triazol-1-yl)undecan-1-ol (1) (4.00 g, $12.64 \mathrm{mmol})$ was dissolved in dry dichlormethane $(60 \mathrm{~mL})$. Triethylamine $(3.37 \mathrm{~mL}, 42.28 \mathrm{mmol})$ was added. Subsequently, the solution was cooled to $0{ }^{\circ} \mathrm{C}$ and methacryloyl chloride $(1.85 \mathrm{~mL}, 18.96 \mathrm{mmol})$ was added. The solution was warmed to room temperature and was stirred for additional $24 \mathrm{~h}$. Afterwards, the reaction mixture was washed twice with saturated $\mathrm{NaHCO}_{3}$ solution. The organic layer was dried over $\mathrm{Na}_{2} \mathrm{SO}_{4}$ and the 
solvent was removed in vacuo, yielding a solid brown residue. Recrystallization from ethanol yields 2 as withe powder $(4.18 \mathrm{~g}, 86 \%)$.

${ }^{1} \mathrm{H}$ NMR $\left(300 \mathrm{MHz}, \mathrm{CDCl}_{3}, \delta\right): 1.17-1.43\left(\mathrm{~m}, 14 \mathrm{H}, \mathrm{CH}_{2}\right), 1.63\left(\mathrm{q}, \mathrm{J}=6.9 \mathrm{~Hz}, 2 \mathrm{H}, \mathrm{O}-\mathrm{CH}_{2}-\mathrm{CH}_{2}\right)$, 1.85-2.00 (m, 5H, N-CH $\left.-\mathrm{CH}_{2}, \mathrm{CH}_{3}\right), 4.12\left(\mathrm{t}, J=6.7 \mathrm{~Hz}, 2 \mathrm{H}, \mathrm{O}-\mathrm{CH}_{2}\right), 4.40\left(\mathrm{t}, J=7.2 \mathrm{~Hz}, 2 \mathrm{H}, \mathrm{N}-\mathrm{CH}_{2}\right)$, $5.53\left(\mathrm{~s}, 1 \mathrm{H},=\mathrm{CH}_{2}\right), 6.08\left(\mathrm{~s}, 1 \mathrm{H},=\mathrm{CH}_{2}\right), 7.21(\mathrm{dd}, J=7.5,4.9 \mathrm{~Hz}, 1 \mathrm{H}), 7.76(\mathrm{td}, J=7.8,1.7 \mathrm{~Hz}, 1 \mathrm{H}), 8.05-8.29$ $(\mathrm{m}, 2 \mathrm{H}), 8.57(\mathrm{~d}, J=4.8 \mathrm{~Hz}, 1 \mathrm{H}) \mathrm{ppm} ;{ }^{13} \mathrm{C} \mathrm{NMR}\left(75 \mathrm{MHz}, \mathrm{CDCl}_{3}, \delta\right): 18.5\left(\mathrm{CH}_{3}\right), 26.1\left(\mathrm{CH}_{2}\right), 26.6\left(\mathrm{CH}_{2}\right)$, $28.7\left(\mathrm{CH}_{2}\right), 29.1\left(\mathrm{CH}_{2}\right), 29.3\left(\mathrm{CH}_{2}\right), 29.4\left(\mathrm{CH}_{2}\right), 29.5\left(\mathrm{CH}_{2}\right), 29.6\left(\mathrm{CH}_{2}\right), 30.3\left(\mathrm{CH}_{2}\right), 50.6\left(\mathrm{~N}-\mathrm{CH}_{2}\right), 64.9$ $\left(\mathrm{O}-\mathrm{CH}_{2}\right), 120.3,121.9,122.9,125.3,136.6,136.7148 .4,149.4,150.5,167.7 \mathrm{ppm}$; FT-IR $\left(\mathrm{cm}^{-1}\right): 652,788$, $854,930,1045,1076,1161,1300,1323,1462,1597,1640,1717,2847,2920,3129 ; \mathrm{C}_{22} \mathrm{H}_{32} \mathrm{~N}_{4} \mathrm{O}_{2}$ : Calcd. C 68.72, H 8.39, N 14.57; found: C 68.57, H 8.41, N 14.31.

\subsubsection{1-(4-(Pyridine-2-yl)-1H-1,2,3-triazol-1-yl)undecanyl-acetate (3)}

The synthesis and purification of 3 was performed analogue to the synthesis of 2 [52]. Thus, 11-(4-pyridin-2-yl)-1H-1,2,3-triazol-1-yl)undecan-1-ol (1) (696 mg, $2.2 \mathrm{mmol}$ ), dry dichloromethane $(15 \mathrm{~mL})$ as solvent and triethylamine $(0.55 \mathrm{~mL}, 4.0 \mathrm{mmol})$ were utilized. Instead of methacryloyl chloride, acetyl chloride $(0.25 \mathrm{~mL}, 3.5 \mathrm{mmol})$ was applied for the synthesis. Recrystallization from ethanol yields 3 as withe powder $(553,69 \%)$.

${ }^{1} \mathrm{H}$ NMR $\left(300 \mathrm{MHz}, \mathrm{CDCl}_{3}, \delta\right): 1.16-1.45\left(\mathrm{~m}, 14 \mathrm{H}, \mathrm{CH}_{2}\right), 1.48-1.74\left(\mathrm{~m}, 2 \mathrm{H}, \mathrm{O}-\mathrm{CH}_{2}-\mathrm{CH}_{2}\right), 1.79-$ $1.97\left(\mathrm{~m}, 2 \mathrm{H}, \mathrm{N}-\mathrm{CH}_{2}-\mathrm{CH}_{2}\right), 2.03\left(\mathrm{~s}, 3 \mathrm{H}, \mathrm{CH}_{3}\right), 4.03\left(\mathrm{t}, J=6.6 \mathrm{~Hz}, 2 \mathrm{H}, \mathrm{O}-\mathrm{CH}_{2}\right), 4.41(\mathrm{t}, J=7.0 \mathrm{~Hz}, 2 \mathrm{H}$, $\left.\mathrm{N}-\mathrm{CH}_{2}\right), 7.16-7.33(\mathrm{~m}, 1 \mathrm{H}), 7.77(\mathrm{t}, J=7.7 \mathrm{~Hz}, 1 \mathrm{H}), 8.04-8.27(\mathrm{~m}, 2 \mathrm{H}), 8.57(\mathrm{~d}, J=3.8 \mathrm{~Hz}, 1 \mathrm{H}) \mathrm{ppm} ;{ }^{13} \mathrm{C}$ NMR (75 MHz, $\left.\mathrm{CDCl}_{3}, \delta\right): 21.2\left(\mathrm{CH}_{3}\right), 26.0\left(\mathrm{CH}_{2}\right), 26.6\left(\mathrm{CH}_{2}\right), 28.7\left(\mathrm{CH}_{2}\right), 29.1\left(\mathrm{CH}_{2}\right), 29.3\left(\mathrm{CH}_{2}\right), 29.4$ $\left(\mathrm{CH}_{2}\right), 29.5\left(\mathrm{CH}_{2}\right), 29.6\left(\mathrm{CH}_{2}\right), 30.4\left(\mathrm{CH}_{2}\right), 50.6\left(\mathrm{~N}-\mathrm{CH}_{2}\right), 64.8\left(\mathrm{O}-\mathrm{CH}_{2}\right), 120.3,121.9,122.9,137.0,148.5$, 149.5, 150.5, 171.4 ppm; $\mathrm{C}_{20} \mathrm{H}_{30} \mathrm{~N}_{4} \mathrm{O}_{2}$ : Calcd. C 67.01, $\mathrm{H}$ 8.44, N 15.63; found: C 66.78, $\mathrm{H} 8.32 \mathrm{~N} 15.44$.

\subsection{Synthesis of Model Complexes}

The 11-(4-(pyridine-2-yl)-1H-1,2,3-triazol-1-yl)undecanyl-methacrylate (2) was dissolved in methanol $(3 \mathrm{~mL}) \cdot \mathrm{M}(\mathrm{OAc})_{2}\left(\mathrm{H}_{2} \mathrm{O}\right) \mathrm{x}$, dissolved in methanol $(2 \mathrm{~mL})$, was added to the ligand solution. The mixture turned to a clear and colored solution (zinc(II) acetate: light yellow; cobalt(II) acetate: purple). Afterwards the solvent was evaporated in vacuo yielding the resulting model complex $\left(\left[\operatorname{Trpy}_{2} \mathrm{Zn}\right]^{2+}\right.$ and $\left[\operatorname{Trpy}_{2} \mathrm{Co}^{2+}\right)$. The utilized masses are summarized in Table 1.

Table 1. Utilized masses for the synthesis of the model complexes ([Trpy $2 \mathrm{Zn}]^{2+}$ and $\left.\left[\operatorname{Trpy}_{2} \mathrm{Co}\right]^{2+}\right)$.

\begin{tabular}{ccccc}
\hline & Educts & $\mathbf{m}$ [mg] & $\mathbf{n}[\mathbf{m m o l}]$ & Yield [mg] \\
\hline$\left[\operatorname{Trpy}_{2} Z \mathbf{Z n}\right]^{2+}$ & 2 & 247 & 0.642 & \multirow{2}{*}{$318(100 \%)$} \\
& $\mathrm{Zn}(\mathrm{OAc})_{2} 2 \mathrm{H}_{2} \mathrm{O}$ & 71 & 0.321 & \\
{$\left[\operatorname{Trpy}_{2} \mathrm{Co}^{2+}\right.$} & 2 & 220 & 0.572 & $291(100 \%)$ \\
\hline
\end{tabular}

$\left[\operatorname{Trpy}_{2} \mathrm{Zn}\right]^{2+}:{ }^{1} \mathrm{H}$ NMR $\left(300 \mathrm{MHz}, \mathrm{CDCl}_{3}, \delta\right): 1.02-1.46\left(\mathrm{~m}, 30 \mathrm{H}, \mathrm{CH}_{2}\right), 1.56-1.79(\mathrm{~m}, 4 \mathrm{H}$, $\left.\mathrm{O}-\mathrm{CH}_{2}-\mathrm{CH}_{2}\right), 1.85-2.00\left(\mathrm{~m}, 18 \mathrm{H}, \mathrm{N}-\mathrm{CH}_{2}-\mathrm{CH}_{2}, \mathrm{CH}_{3}\right), 4.14\left(\mathrm{t}, \mathrm{J}=6.6 \mathrm{~Hz}, 4 \mathrm{H}, \mathrm{O}-\mathrm{CH}_{2}\right), 4.44(\mathrm{t}$, $\left.J=7.2 \mathrm{~Hz}, 4 \mathrm{H}, \mathrm{N}-\mathrm{CH}_{2}\right), 5.56\left(\mathrm{~s}, 2 \mathrm{H},=\mathrm{CH}_{2}\right), 6.10\left(\mathrm{~s}, 2 \mathrm{H},=\mathrm{CH}_{2}\right), 7.33(\mathrm{~s}, 2 \mathrm{H}), 7.86(\mathrm{t}, J=7.5 \mathrm{~Hz}, 2 \mathrm{H})$, 8.06-8.19 (m, 4H), 8.71 (s, 2H) ppm; FT-IR $\left(\mathrm{cm}^{-1}\right): 617,667,787,845,930,1045,1161,1296,1323,1415$, $1454,1597,1717,2851,2920,3129$.

$\left[\operatorname{Trpy}_{2} \mathrm{Co}^{2+}\right.$ : FT-IR $\left(\mathrm{cm}^{-1}\right):$ 606, 644, 788, 852, 930, 1007, 1037, 1165, 1296, 1327, 1385, 1454, 1593, $1716,2855,2924,3129$.

\subsection{Synthesis of the Polymer Networks}

All polymerizations were performed in a $50 \mathrm{~mL}$ one-neck round bottom flask. A stock solution of the initiator, 2,2'-azobis(2-methylpropionitril) (AIBN), in dry $N, N$-dimethylformamide (DMF) was prepared. Compound 2, the respective monomer (methyl-methacrylate (MMA) in case of P1 to P5, 
ethyl-methacrylate (EMA) in case of P6 to P10 or butyl-methacrylate (BMA) in case of P10 to P13 and the crosslinker (triethylene glycol dimethacrylate (TEGDMA)) were added into the flask. Subsequently, the required amount of the initiator stock solution was added. The monomer-to-initiator ratio for all polymerizations was 100 to 1 . Afterwards the residual volume of DMF was added to reach the desired concentrations of $1 \mathrm{M}$ (P1 and P2) or $2 \mathrm{M}$ (P3 to P13), respectively. The solution was purged with nitrogen for $45 \mathrm{~min}$. Subsequently, the mixture was stirred in a preheated oil bath at $70^{\circ} \mathrm{C}$ overnight. At the end of the polymerization the crude product was purified by the usage of dialysis (MWCO: $1000 \mathrm{~g} / \mathrm{mol}$, THF). The solvent was changed two times each day for three days. The respective used quantities of all substances are listed in Tables S1, S3 and S5. The ${ }^{1} \mathrm{H}$ NMR spectra of the polymer networks (P1 to P13) are shown in the supporting information (SI). The results of the of the elemental analysis and the DSC and TGA investigations are shown in Tables S2, S4 and S6. All analytics of the polymers are summarized in the SI.

\subsection{Synthesis of the Metallo Polymer Networks}

For the synthesis of the metallopolymer networks (P1-Zn to P13-Zn and P1-Co to P13-Co) the polymers (P1 to P13) were swollen in chloroform $(6 \mathrm{~mL})$ resulting in gels. The calculated amount of either zinc(II) acetate or cobalt(II) acetate was dissolved in methanol $(2 \mathrm{~mL})$ and was added to the swollen polymer network. Afterwards, the solvent was evaporated. The resulting metallopolymer network was dried in vacuo at $40^{\circ} \mathrm{C}$ and after that for one day at 80 to $90^{\circ} \mathrm{C}$ in an oven. The respective used quantities of the substances are listed in Tables S7, S9 and S11. The results of the elemental analysis and the DSC and TGA investigations are shown in Tables S8, S10 and S12. All analytics of the polymers are summarized in the SI.

\section{Results and Discussion}

\subsection{Synthesis of the Triazole-Pyridine Monomer and Model System}

In order to later synthesize polymers, the preparation of ligand-containing monomer was required. Furthermore, a low molar mass model system, mimicking the ligand in the polymer enabling the investigation of the complex formation, is useful. The synthesis of this model-system and the monomer was performed by a two-step reaction, which is depicted in Scheme 1. First, 11-(4-(pyridin-2-yl)-1H-1,2,3-triazol-1-yl)undecan-1-ol was prepared applying a copper catalyzed 1,3-dipolar cycloaddition of 11-bromo-1-undecanol, 2-ethynylpyridine and sodium azide [51]. Afterwards, an esterification was performed using triethylamine as base to shift the equilibrium towards the product side. As electrophile, methacryloyl chloride (in case of the monomer 2) and acetyl chloride (in case of the model system 3) were utilized. The reaction for the monomer is also reported in the literature [52] and was adapted for the model system. The products were characterized with ${ }^{1} \mathrm{H}$ and ${ }^{13} \mathrm{C}$ NMR spectroscopy as well as elemental analysis. The spectra are shown in the supporting information (Figures S1 to S4). 


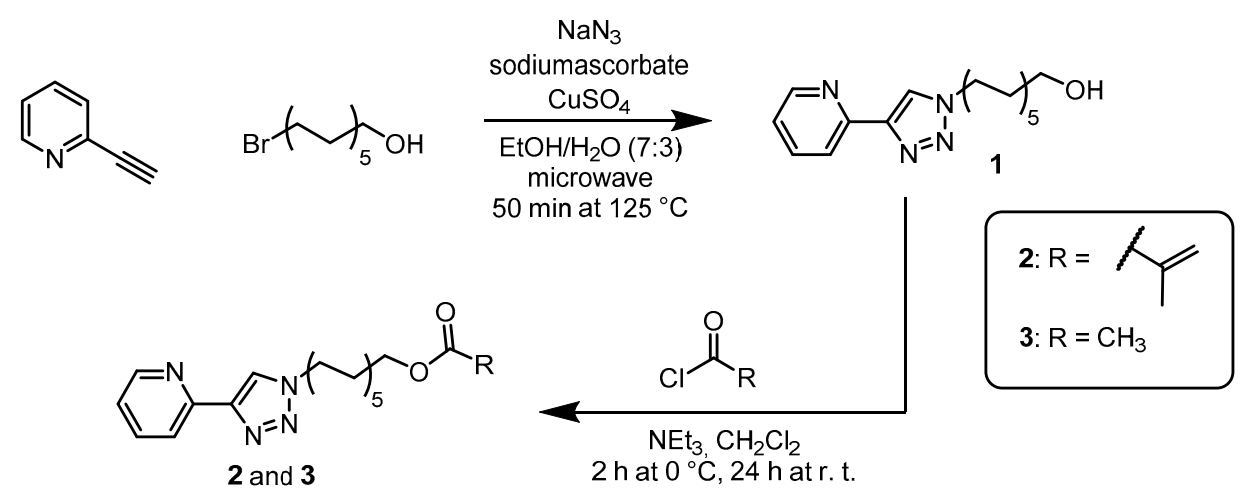

Scheme 1. Schematic representation of the synthesis of 11-(4-(pyridin-2-yl)1H-1,2,3-triazol1-yl)undecanyl-methacrylate (2) and 11-(4-(pyridin-2-yl)-1H-1,2,3-triazol-1-yl)undecanyl- acetate (3). [52] First step: synthesis of 11-(4-(pyridin-2-yl)-1H- 1,2,3-triazol-1-yl)undecan-1-ol (1) via a cooper catalyzed 1,3-dipolar cycloaddition. Second step: Esterification of 11-(4-(pyridin-2-yl)-1H1,2,3-triazol-1-yl)undecan-1-ol with acetyl chloride or methacryloyl chloride.

\subsection{Isothermal Titration Calorimetry Investigations (ITC)}

The synthesized model system (11-(4-[pyridin-2-yl]-1H-1,2,3-triazol-1-yl)undecanyl-acetate) was utilized for ITC investigations in order to determine the stoichiometry $\left(\mathrm{L}_{\mathrm{n}} \mathrm{M}\right)$ of ligand to different metal ions as well as the complex association constant $\left(K_{a}\right)$. Furthermore, the complex dissociation constant $\left(\mathrm{K}_{\mathrm{d}}\right)$ can be determined, which corresponds to $\mathrm{K}_{\mathrm{a}}{ }^{-1}$. These values are of great interest in order to evaluate the strength of the supramolecular unit and to correlate these molecular properties with the resulting properties of the material.

For the measurement, the salt was dissolved in methanol and put into the cell. The model system (3) was also dissolved in methanol and titrated to the solution of the salt at $303 \mathrm{~K}$. Different salts have been investigated. Cobalt(II) acetate and zinc(II) acetate revealed good results (i.e., sufficient binding with a relatively low binding constant) as switching unit for shape-memory polymers, which are summarized in Table 2 (the ITC curves of the measurements are shown in the supporting information Figures S5 and S6).

Table 2. Determined complex dissociation and association constants and stoichiometry for zinc(II) and cobalt(II) acetate and the model system by titration calorimetry investigations (ITC) investigations.

\begin{tabular}{cccc}
\hline Metal Salt & $\mathbf{K}_{\mathbf{d}}$ & $\mathbf{K}_{\mathbf{a}}$ & $\mathbf{n}$ \\
\hline $\mathrm{Zn}(\mathrm{OAc})_{2}$ & $2.95 \times 10^{-3}$ & $3.39 \times 10^{2}$ & 1.8 \\
$\mathrm{Co}(\mathrm{OAc})_{2}$ & $3.74 \times 10^{-4}$ & $2.68 \times 10^{3}$ & 2.4 \\
\hline
\end{tabular}

These results show that both metal salts are able to form complexes with the synthesized ligand. Therefore, two ligands bind one metal ion. The association constant for the cobalt(II) complex is higher than of the zinc(II) complex. Consequently, the cobalt(II) complex seems to be more stable than the formed zinc(II) complex. Generally, the complexation constants are relatively low compared to other metal complexes such as terpyridine [53]. Therefore, these complexes seems to be well-suited for the utilization within shape-memory polymers, since the metal-ligand interaction can easily be addressed by an external stimulus and the supramolecular unit can represent the reversible part of a shape-memory polymer.

\subsection{Model Complexes}

According to the ITC-results, two model metal complexes were synthesized in order to analyze the metallopolymers later in a more detailed fashion. By this manner it is possible to compare the spectra of the model complexes with those of the metallopolymer networks, e.g., from NMR or FT-IR 
spectroscopy. Therefore, monomer (2) was dissolved in methanol and zinc(II) acetate dihydrate or cobalt(II) acetate tetrahydrate, respectively, was added. The ratio obtained from ITC was utilized for the complex synthesis. Evaporating the solvent yields the complexes $\left[\operatorname{Trpy}_{2} \mathrm{Zn}\right]^{2+}$ and $\left[\operatorname{Trpy}_{2} \mathrm{Co}\right]^{2+}$. The reaction for the synthesis of the model complexes is depicted in Scheme 2.

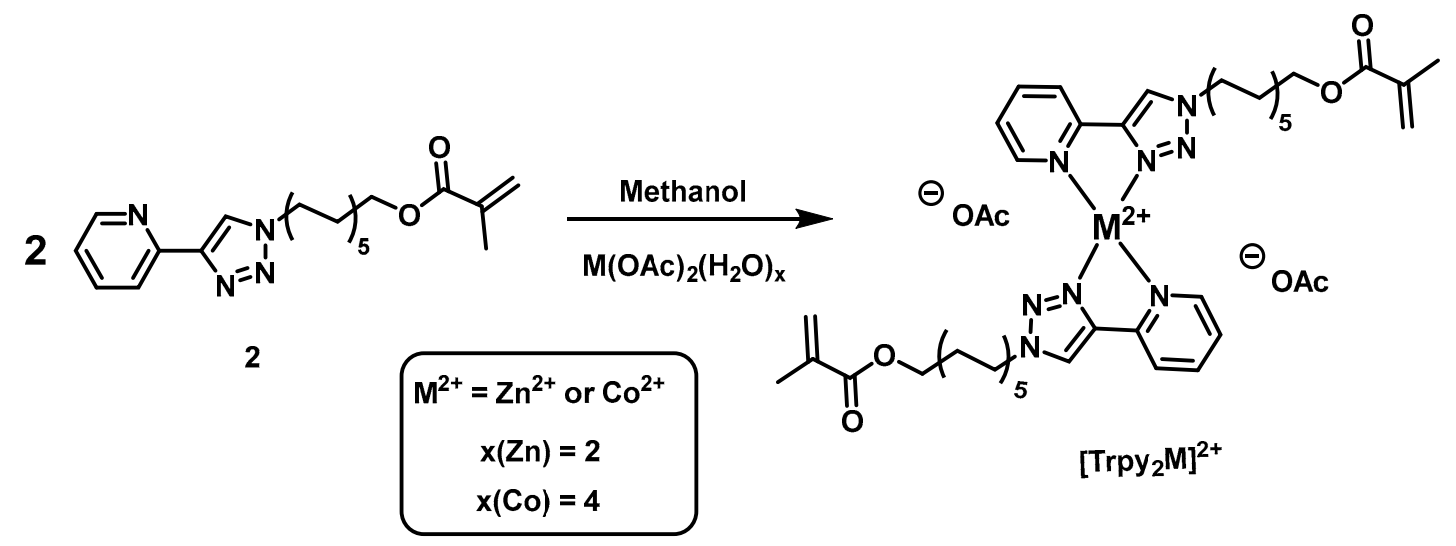

Scheme 2. Schematic representation of the synthesis of the model complexes $\left[\operatorname{Trpy}_{2} \mathrm{Zn}\right]^{2+}$ and $\left[\operatorname{Trpy}_{2} \mathrm{Co}\right]^{2+}$.

The obtained complexes $\left(\left[\operatorname{Trpy}{ }_{2} \mathrm{Zn}\right]^{2+}\right.$ and $\left[\operatorname{Trpy}_{2} \mathrm{Co}\right]^{2+}$ ) were subsequently investigated using FT-IR spectroscopy and in the case of the zinc(II) containing complex by ${ }^{1} \mathrm{H}$ NMR spectroscopy. The resulting spectra were compared with those of the monomer (2). A zoom of the ${ }^{1} \mathrm{H}$ NMR spectra of 2 and $\left[\operatorname{Trpy}_{2} \mathrm{Zn}\right]^{2+}$ is shown in Figure 2a. By comparing both spectra, it can be seen that the complexation leads to a shift of the ligand signals (from 7.24 to $7.33 \mathrm{ppm}$; from 7.77 to $7.86 \mathrm{ppm}$ and from 8.57 to $8.71 \mathrm{ppm})$ in the aromatic area within the ${ }^{1} \mathrm{H}$ NMR spectrum. The FT-IR spectra of 2 and the model complexes $\left(\left[\operatorname{Trpy}{ }_{2} \mathrm{Zn}\right]^{2+}\right.$ and $\left.\left[\operatorname{Trpy}_{2} \mathrm{Co}\right]^{2+}\right)$ are shown in Figure $2 \mathrm{~b}$. An increase of the $\mathrm{C}=\mathrm{N}$ valence vibration at $1597 \mathrm{~cm}^{-1}$ can be found for both complexes. Furthermore, some signals in the finger print area are shifted about a few $\mathrm{cm}^{-1}$. Thus, a successful complex formation can be visualized using IR spectroscopy.

(a)

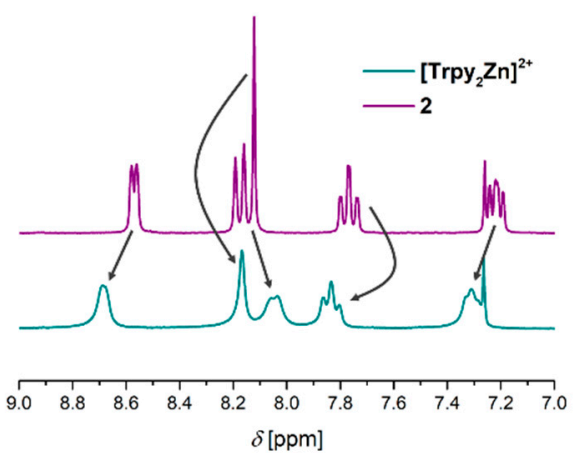

(b)

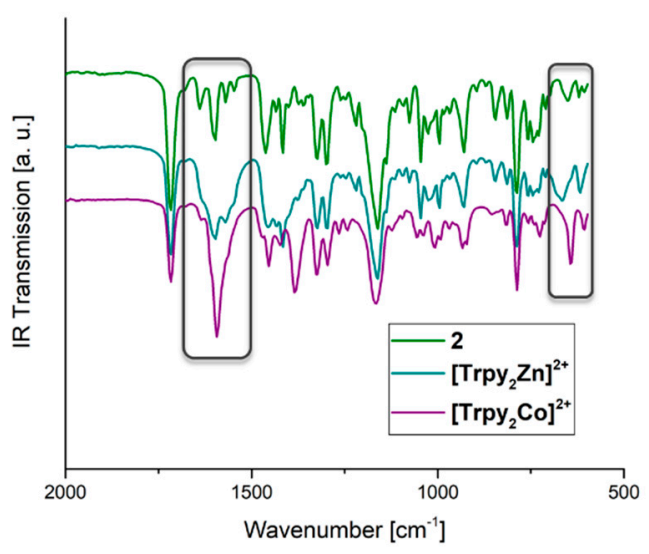

Figure 2. (a) Zoom of the ${ }^{1} \mathrm{H}$ NMR spectra of 2 and the model complex containing zinc(II) ([Trpy $\mathrm{Zn}^{2+}$ ) $\left(300 \mathrm{MHz}, \mathrm{CDCl}_{3}\right)$; (b) zoom of the FT-IR spectra of 2 and the model complexes ([Trpy $\left.2 \mathrm{Zn}\right]^{2+}$ and $\left.\left[\operatorname{Trpy}_{2} \mathrm{Co}\right]^{2+}\right)$. 


\subsection{Polymer Networks}

All polymer networks (P1 to P13) were synthesized via free radical polymerization (FRP). Azobis(isobutyronitrile) (AIBN) was utilized as initiator. As monomers, methyl-, ethyl- or butyl methacrylate were applied. Furthermore, a crosslinker, TEGDMA, as well as the synthesized ligand monomer 2, were used. The amounts of the ligand and the crosslinker were varied. The polymer networks feature a different crosslinking density $(5 \%$ and $10 \%)$ and a different content of the ligand monomer $(5 \%, 10 \%$ and $20 \%)$ in order to evaluate both influences later on. After the polymerization, none of the polymer networks was soluble in any common solvent. It was just possible to form gels by using for example chloroform, dichloromethane, DMF and THF. Thus, a successful formation of a polymer network can be assumed.

All resulting polymers were characterized by ${ }^{1} \mathrm{H}$ NMR spectroscopy (see Figures S33 to S35) in the gel state and elemental analysis. These two methods were used to determine the ratio of the alkyl methacrylate to the ligand moieties assuming that the proportion of the crosslinker corresponds to the theoretical one. For NMR spectroscopy, the insoluble polymer networks were swollen in the NMR tube by adding deuterated chloroform. The theoretical proportion of the ligand units and the crosslinker in the polymer were assumed as fixed values and just the corresponding alkyl methacrylate content was determined. In the case of the NMR spectrum the ligand signals between 7.16 and $8.58 \mathrm{ppm}$ were set in relation to those of the $\mathrm{O}-\mathrm{CH}_{3}$ group of MMA (3 to $4 \mathrm{ppm}$ ), to the $\mathrm{O}-\mathrm{CH}_{2}$ group in the case of EMA and BMA ( 3 to $5 \mathrm{ppm}$ ), respectively. It was important to note that the $\mathrm{O}-\mathrm{CH}_{2}$ groups of the crosslinker and ligand monomer appear in the same range, so these protons had to be considered as well. In the case of EMA and BMA as main monomer, the signal of the $\mathrm{O}-\mathrm{CH}_{2}$ groups gets broader and also the $\mathrm{N}-\mathrm{CH}_{2}$ group at $4.41 \mathrm{ppm}$ of the ligand monomer was not further base line separated and these protons has also to be considered. A typical spectrum of a polymer NMR is shown in Figure 3.

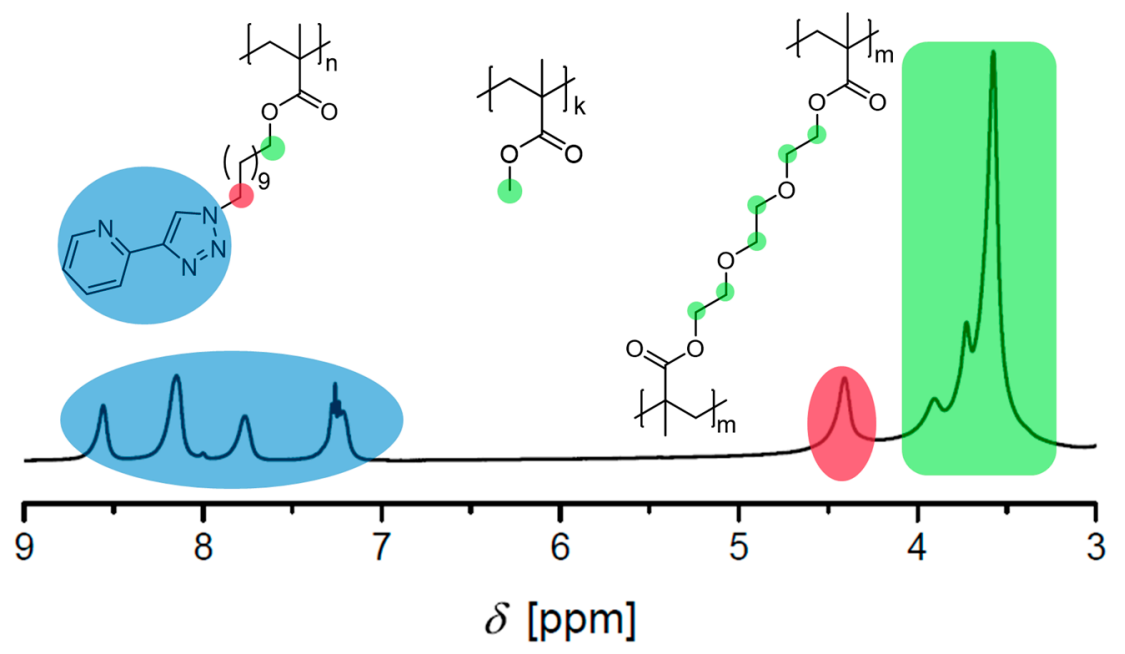

Figure 3. Zoom of the ${ }^{1} \mathrm{H}$ NMR spectrum of the polymer network $\mathrm{P} 3$ as example for the determination of the ratio of MMA to the crosslinker (triethylene glycol dimethacrylate (TEGDMA)) and the ligand monomer. Blue and red: signals of the ligand, green: the signals of the $\mathrm{O}-\mathrm{CH}_{2}$ and $\mathrm{O}-\mathrm{CH}_{3}$ groups $\left(400 \mathrm{MHz}, \mathrm{CDCl}_{3}\right)$.

The calculation of the composition by the usage of the elemental analysis was performed using the determined values for the nitrogen. The theoretical proportion of the ligand units and the crosslinker in the polymer were assumed as fixed values and just the corresponding alkyl methacrylate content was determined. The initiator was neglected for the calculations.

The compositions of all polymer networks (P1 to P13) have been calculated in the same way and are summarized in Table 3. All found values for the amount of the main monomer in the polymer networks fit well to the theoretical expected values. However, both methods feature a certain limitation 
for the determination of the exact composition of polymer networks. In both cases it is not possible to determine the amount of cross-linker, consequently, the content must be assumed as fixed by the theoretical values. Nevertheless, the approximate ratio of the ligand to the main monomer could be revealed for nearly all polymers.

Table 3. Theoretical and calculated values for the composition of the polymer networks P1 to P13.

\begin{tabular}{|c|c|c|c|c|c|c|}
\hline & \multirow{2}{*}{$\begin{array}{l}\text { Main } \\
\text { Monomer }\end{array}$} & \multirow{2}{*}{$\begin{array}{l}\text { Theoretical Units } \\
\text { of the TEGDMA }\end{array}$} & \multirow{2}{*}{$\begin{array}{l}\text { Theoretical Units } \\
\text { of the Ligand }\end{array}$} & \multicolumn{3}{|c|}{$\begin{array}{l}\text { Units of the Main Monomer } \\
\text { (MMA, EMA or BMA) }\end{array}$} \\
\hline & & & & Theoretical & $\begin{array}{c}\text { Found by } \\
\text { NMR }\end{array}$ & $\begin{array}{c}\text { Found by } \\
\text { EA }\end{array}$ \\
\hline P1 & \multirow{5}{*}{ MMA } & 1 & 1 & 20 & 18.3 & 14.6 \\
\hline P2 & & 1 & 2 & 20 & 19.7 & 18.5 \\
\hline P3 & & 1 & 4 & 20 & 20.3 & 22.0 \\
\hline P4 & & 2 & 2 & 20 & 21.7 & 22.7 \\
\hline P5 & & 2 & 4 & 20 & 16.7 & 21.1 \\
\hline P6 & \multirow{5}{*}{ EMA } & 1 & 1 & 20 & 20.0 & 19.7 \\
\hline P7 & & 1 & 2 & 20 & 16.0 & 16.1 \\
\hline P8 & & 1 & 4 & 20 & 21.0 & 21.3 \\
\hline P9 & & 2 & 2 & 20 & 18.0 & 18.2 \\
\hline P10 & & 2 & 4 & 20 & 20.5 & 21.5 \\
\hline P11 & \multirow{3}{*}{ BMA } & 1 & 1 & 20 & 21.0 & 21.6 \\
\hline P12 & & 1 & 2 & 20 & 21.0 & 19.7 \\
\hline P13 & & 2 & 2 & 20 & 19.5 & 21.0 \\
\hline
\end{tabular}

\subsection{Metallopolymer Networks}

For the synthesis of the metallopolymer networks, the polymer networks (P1 to P13) were mixed with the corresponding metal salts. This reaction leads to supramolecular crosslinking by the formation of the ligand metal ion complex. As metal salts, zinc(II) acetate dihydrate (P1-Zn to P13-Zn) and cobalt(II) acetate tetrahydrate (P1-Co to P13-Co) were utilized. For the formation of the complex, the polymer network was swollen in chloroform. The metal salt was dissolved in methanol and added to the swollen polymer. After evaporation of the solvent, the metallopolymer networks (P1-Zn/Co to P13-Zn/Co) were obtained. The amount of metal salt was calculated based on the results of the ITC investigations. Thus, a metal-ligand ratio of 1:2 was applied for the synthesis of the supramolecular networks.

The successful formation of the metallopolymer networks was verified via FT-IR and ${ }^{1} \mathrm{H}$ NMR spectroscopy analogous to the model complexes. Exemplarily, the FT-IR spectra of the polymer network P8 and the corresponding metallopolymer networks (P8-Zn and P8-Co) are depicted in Figure 4. The largest change could be revealed for the $\mathrm{N}=\mathrm{C}$ valence vibration at $1605 \mathrm{~cm}^{-1}$, which increases during complexation similar to the model complexes mentioned above. The signal in the fingerprint region at about $664 \mathrm{~cm}^{-1}$ shows an increase in intensity after metallopolymer formation: They revealed the same changes as found for the monomer (2) and the model complexes ([Trpy $2 \mathrm{Zn}]^{2+}$ and $\left.\left[\operatorname{Trpy}_{2} \mathrm{Co}\right]^{2+}\right)$. These variations in the IR-spectra indicate a successful complex formation within the polymer networks resulting in a dual-polymer network structure featuring, on the one hand, an irreversible covalent and, on the other hand, a reversible supramolecular unit. Furthermore, the IR spectra were recorded and compared for all polymers and metallopolymer networks, which is depicted in the supporting information (Figures S37 to S49). 


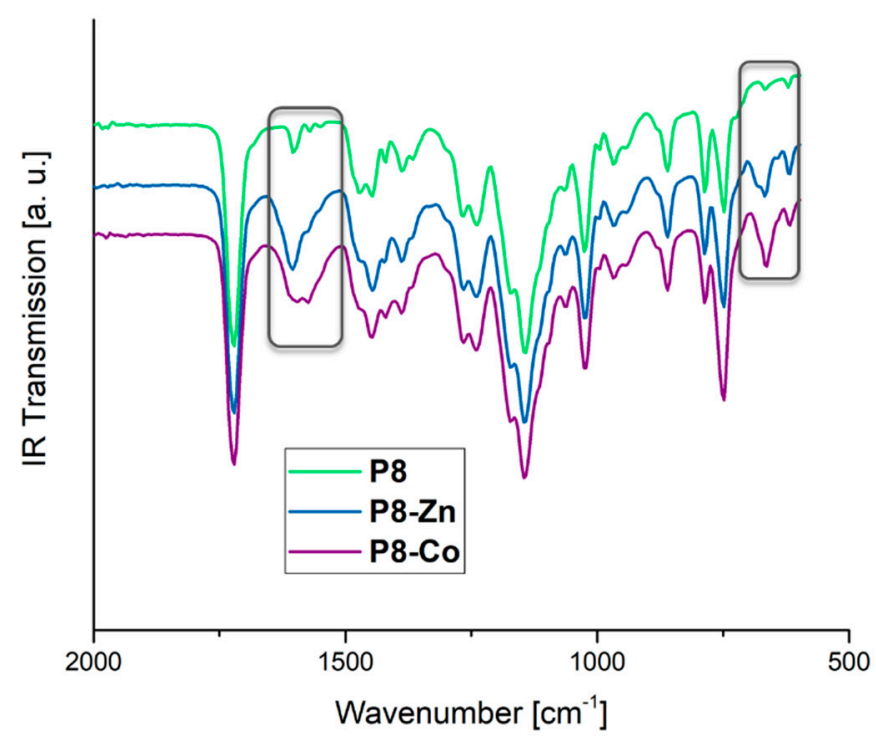

Figure 4. FT-IR spectra of the polymer network (P8) and the corresponding metallopolymer networks (P8-Zn and P8-Co).

Exemplarily, the ${ }^{1} \mathrm{H}$ NMR spectrum was recorded for the metallopolymer network P10-Zn, which contains zinc(II) ions. For this purpose, P10-Zn was swollen in the NMR tube by adding deuterated chloroform and the spectrum was obtained from the gel of the metallopolymer network. The zoom of the ${ }^{1} \mathrm{H}$ NMR spectra of the polymer network P10 and the corresponding metallopolymer network P10-Zn is shown in the SI in Figure S36. Thus, a shift of the aromatic signals similar to the found shifts of the model complexes could be revealed indicating a successful complexation. However, further NMR-spectra of the other metallopolymers could not be obtained due the very low solubility as well as, in case of cobalt-based polymers, the paramagnetic behavior.

\subsection{Thermal Behaviour of the Polymer and Metallopolymer Networks}

The thermal behavior of the polymer networks P1 to P13 and the metallopolymer networks (P1-Zn to P13-Zn and P1-Co to P13-Co) was investigated by DSC and thermogravimetric analysis (TGA). The glass transition temperatures $\left(T_{g}\right)$ could be obtained by DSC measurements. All polymer and metallopolymer networks show a very broad $T_{g}$. The TGA measurement provided the values for the degradation temperatures. The values for the glass transition temperature $\left(T_{g}\right)$ and the degradation temperature $\left(T_{d}\right)$ (Tables S2, S4 and S6) as well as the DSC (Figures S7 to S19) and TGA curves (Figures S20 to S32) are summarized in the supporting information. The results of the DSC measurement show, as expected, that the glass transition temperatures of the polymer and metallopolymer networks decrease with the length of the alkyl chain of the ester in the methacrylate [54]. Consequently, the MMA containing polymers (P1 to P5) and corresponding metallopolymers ( $\mathrm{P} 1-\mathrm{Zn} / \mathrm{Co}$ to $\mathrm{P} 5-\mathrm{Zn} / \mathrm{Co}$ ) feature the highest glass transition temperatures, those consisting of BMA (P11 to P13, P11-Zn/Co to $\mathrm{P} 13-\mathrm{Zn} / \mathrm{Co}$ ) the lowest ones.

Besides the effect of the alkyl chain, there are also other trends that can be found. It turns out that the glass transition temperature of the polymer network is in general lower than these of the corresponding metallopolymer networks (Figure 5) indicating a successful complexation. Furthermore, nearly all of the investigated metal-containing polymers featured one very broad glass transition. Consequently, the activation of the metal-complexes of the metallopolymers cannot be detected by DSC or at least cannot be separated from the $T_{g}$. 


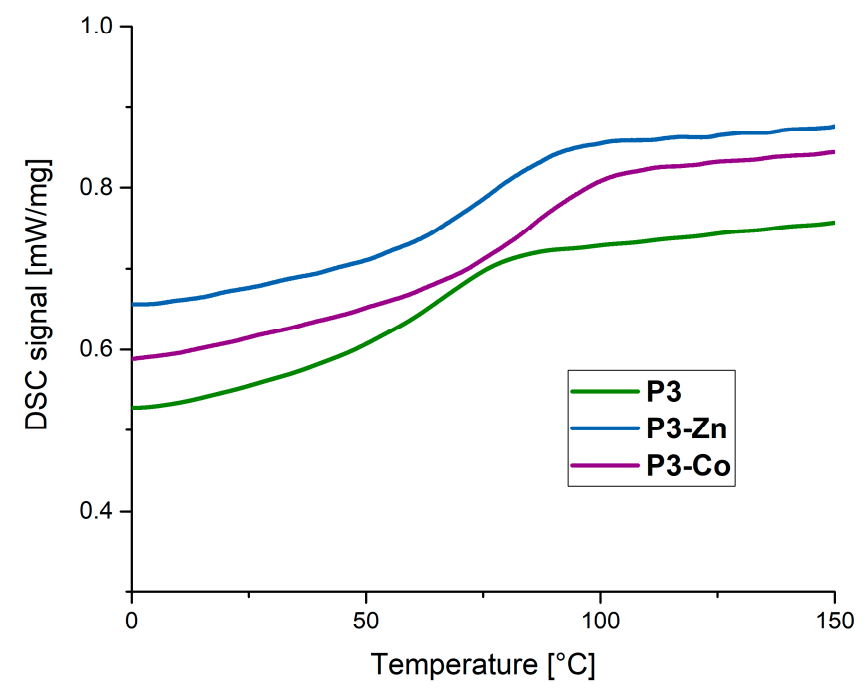

Figure 5. Differential scanning calorimetry (DSC) curves of the polymer network P3 (MMA, 5\% TEGDMA, 20\% Ligand, green) and the corresponding metallopolymer networks. Blue: P3-Zn (zinc (II) containing metallopolymer network). Purple: P3-Co (cobalt (II) containing metallopolymer network).

If both metallopolymers based on one polymer networks are compared, (Figure 5), it can be revealed that the glass transition temperature for the cobalt(II) ion containing metallopolymers is higher than that of the metallopolymer networks based on zinc(II) ions. These fit very well with the further ITC studies which showed a lower association constant for the zinc(II) containing complex.

An influence of the ligand content can also be observed. All polymers and metallopolymers with a higher amount of the ligand generally feature lower glass transition temperatures compared to those with a smaller amount of ligand monomer. This behavior can also be explained by the plasticizer effect of the long alkyl chain based ligand entity.

The TGA measurement revealed values for the degradation temperatures of the polymer and the metallopolymer networks. They were performed under normal atmosphere. All polymers are stable above $200{ }^{\circ} \mathrm{C}$, most also above $250^{\circ} \mathrm{C}$. It could be observed that the cobalt(II) ion containing metallopolymer networks in general featured a slightly lower degradation temperature than the zinc(II) ion containing metallopolymer networks.

Exemplarily, metallopolymer network P12-Zn was characterized by temperature-dependent Raman spectroscopy in order to reveal the temperature-dependent binding of the metal complexes. However, even up to $150^{\circ} \mathrm{C}$, no change in the Raman spectrum could be observed. The spectra are depicted in the supporting information in Figure S50. Consequently, no complete decomplexation can be revealed indicating that a potential dynamic behavior will be based on exchange reactions, which is typically found for vitrimeric systems [55]. Similar findings were previously also reported for other metallopolymer systems [56].

\subsection{Shape-Memory Ability of the Metallopolymer Networks}

To investigate the shape-memory properties of the synthesized metallopolymer networks (P1-Zn to P13-Zn and P1-Co to P13-Co), a permanent shape had to be determined by an initial process. Therefore, the corresponding metallopolymer was pressed at $130^{\circ} \mathrm{C}$ with a pressure between 1 to $4 \mathrm{t}$ in a special mold. By this manner, small rectangular polymer samples could be fabricated. Consequently, the rectangular shape was the permanent shape (see Figure 6). Afterwards, the metallopolymer network, in its permanent shape, was heated up to $90^{\circ} \mathrm{C}$, twisted and cooled to room temperature. This was the programming step of the temporary shape. The metallopolymer network stayed in its new form until it was heated up again to $90^{\circ} \mathrm{C}$. 


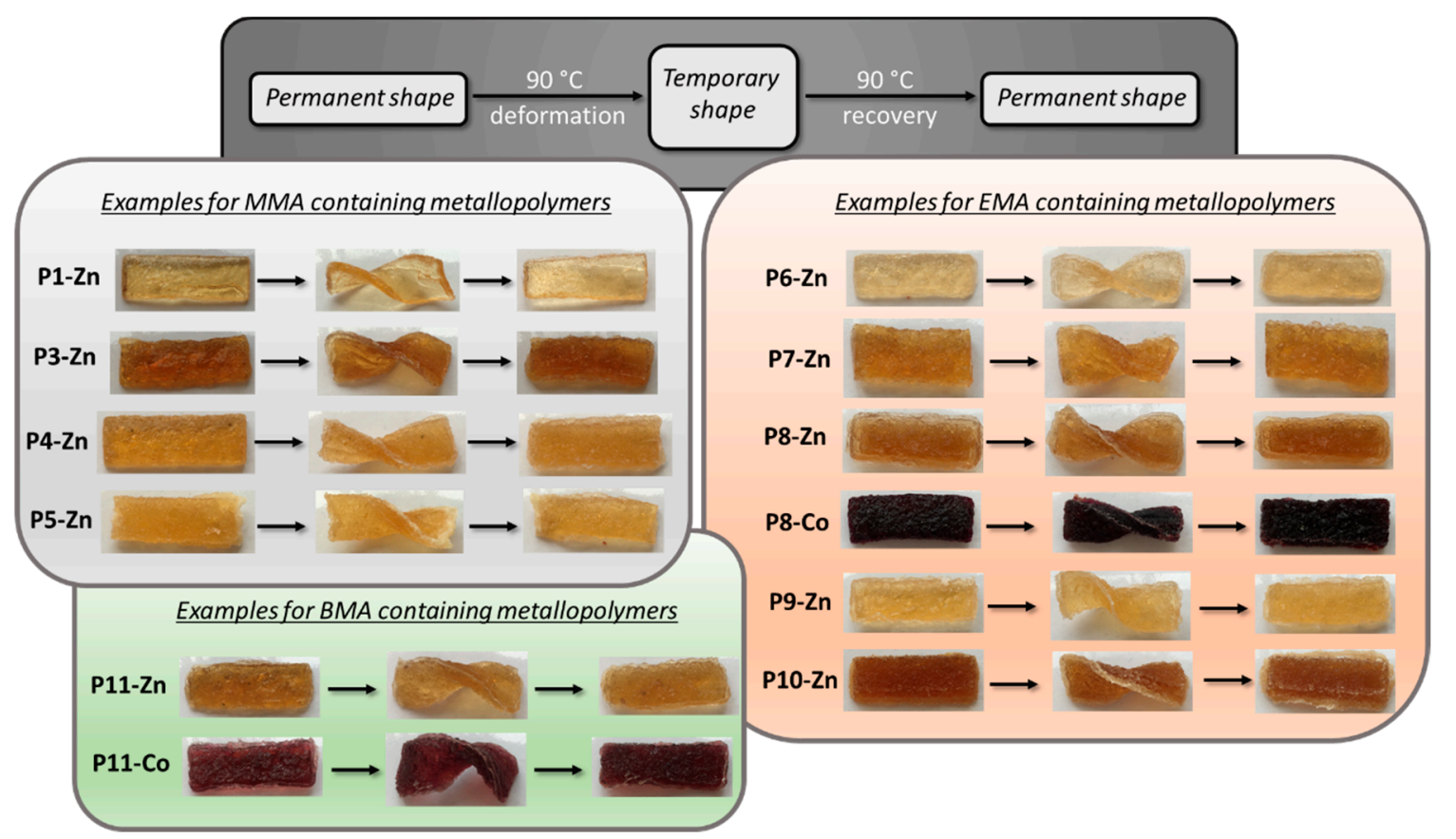

Figure 6. Schematic representation (grey) and photo series of the shape-memory test of different metallopolymer networks containing MMA (light grey), EMA (red) and BMA (green).

During the pressing of the polymers it was found that in general the zinc(II) containing metallopolymer networks could be processed easier than the corresponding ones containing cobalt(II). For some metallopolymer networks, mostly those containing cobalt(II), it was not even possible to press the metallopolymer network into a smooth transparent specimen. In these cases, the samples were crumbly and brittle at room temperature.

In general, nearly all metallopolymer networks featured shape-memory behavior, even those featuring an insufficient processing step. The shape recovery just took a few seconds at $90{ }^{\circ} \mathrm{C}$. The polymers containing butyl methacrylate could be deformed the easiest followed by those consisting of ethyl methacrylate. Those based on methyl methacrylate were the hardest and it was difficult to deform them at $90^{\circ} \mathrm{C}$, which is caused by the high $T_{g}$ of the metallopolymer networks.

The metallopolymer network P12-Zn was chosen for testing of the triple-shape-memory effect, since it was very soft and flexible at $90{ }^{\circ} \mathrm{C}$. Thus, it could be revealed that the polymer can fix more than one temporary shape (Figure 7). Therefore, it first was heated up to $90{ }^{\circ} \mathrm{C}$, elongated at this temperature and after that cooled to room temperature. This elongated form is the temporary shape A. Subsequently, it was heated up to $50^{\circ} \mathrm{C}$, twisted at this temperature and cooled to room temperature. This elongated and twisted form is the temporary shape B. Heating the polymer up to $50^{\circ} \mathrm{C}$ leads to the recovery of the temporary shape $\mathrm{A}$, which was not twisted anymore but elongated. Heating the polymer again up to $90^{\circ} \mathrm{C}$ leads to the recovery of the original permanent shape under shrinking. 


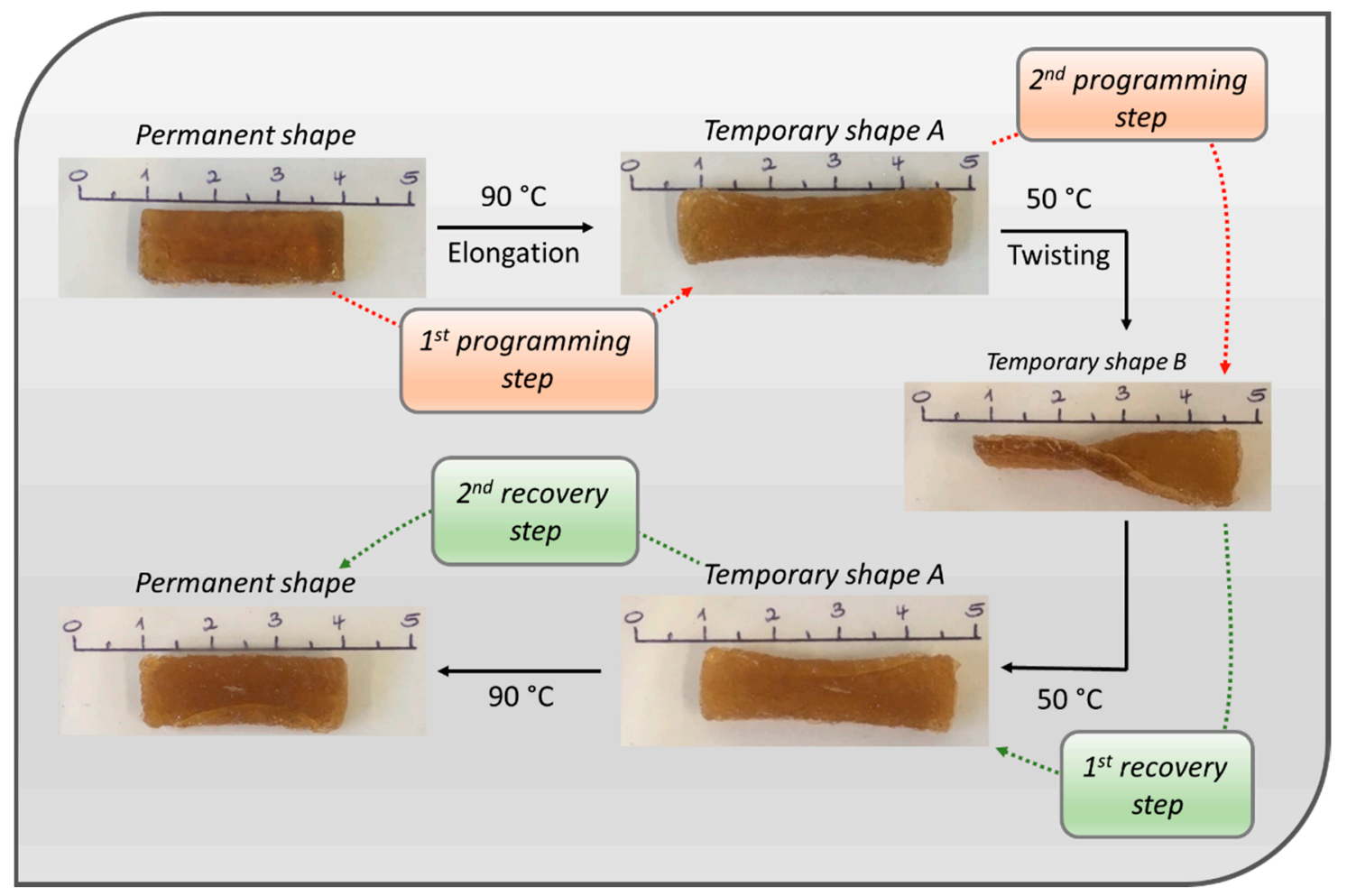

Figure 7. Photo series of the triple-shape-memory test of the metallopolymer network P12-Zn.

To determine the fixity and recovery rates of the synthesized metallopolymer networks and also to compare them regarding their different composition, selected samples were investigated using a cyclo-mechanic-tests. The metallopolymer networks P1-Zn, P6-Zn, P7-Zn, P8-Zn and P11-Zn were chosen for the test, to investigate the influence of the different compositions. P1-Zn, P6-Zn and P11-Zn all consist of 5\% crosslinker and 5\% ligand, just the main monomer is different, so these three measurements where considered as useful to compare the influence of the used main monomer. The metallopolymer networks P6-Zn, P7-Zn and P8-Zn just differ in the content of the ligand, so these three polymers were assumed to be helpful to investigate the influence of the ligand content on the shape-memory abilities. For each sample the measurement was performed three times. The strain fixity rate $\left(R_{f}\right)$ quantifies the ability to fix a mechanical deformation $\left(\varepsilon_{m}\right)$ and leads to the temporary shape $\left(\varepsilon_{u}\right)$ [20]. Furthermore, the strain recovery rate $\left(R_{r}\right)$, which quantifies the ability to restore the mechanical deformation of the permanent shape $\left(\varepsilon_{p}\right)$, can be determined. The test is usually repeated several times. The number of repeating corresponds to the number of cycles $(N)$ [20]. The values for $R_{f}$ and $R_{r}$ can be calculated by Equations (1) and (2).

$$
\begin{gathered}
R_{f}(N)=\varepsilon_{u}(N) / \varepsilon_{m}(N) \times 100 \\
R_{r}(N)=\left(\varepsilon_{m}(N)-\varepsilon_{p}(N)\right) /\left(\varepsilon_{m}(N)-\varepsilon_{p}(N-1)\right) \times 100 .
\end{gathered}
$$

For the measurement, all metallopolymer samples were heated to $90{ }^{\circ} \mathrm{C}$ (with the exception of the metallopolymer sample P1-Zn, which was heated to $110^{\circ} \mathrm{C}$ ). Subsequently, the sample was turned in a linear ramp until the shear stress reached $18,000 \mathrm{~Pa}$, leading to the deformation of the sample. The shear stress was kept constant during the following cooling step of the sample. At a temperature of about $25^{\circ} \mathrm{C}$, the shear stress was reduced to $0 \mathrm{~Pa}$ (linear ramp, $20 \mathrm{~Pa} / \mathrm{s}$ ) and the sample was again heated to $90{ }^{\circ} \mathrm{C}$ (respectively $110{ }^{\circ} \mathrm{C}$ for P1-Zn). The resulting 3D plot (stress-strain-temperature diagram) of the first cycle of the sample P6-Zn is shown in Figure 8. The revealed values for $\varepsilon_{p}, \varepsilon_{m}, \varepsilon_{u}$, as well as the plot of the first cycle, are summarized in the supporting information (Table S13, Figures S51 to S55) for all investigated metallopolymer networks. The calculated values for the fixity and 
recovery rates for the samples P1-Zn, P6-Zn, P7-Zn, P8-Zn and P11-Zn are shown in Table 4. It was found that nearly all investigated metallopolymer networks reveal very good fixity (above $98 \%$ ) and recovery rates (above 95\%) and also no loss of the shape-memory ability could be observed during the three cycles. Just the recovery rate of the metallopolymer network which consists of MMA was a bit lower. Beside this fact, no significant influence of the composition could be observed caused by the fact that nearly all investigated networks show a very good shape-memory performance. Just the switching temperature differs depending on the used main monomer.

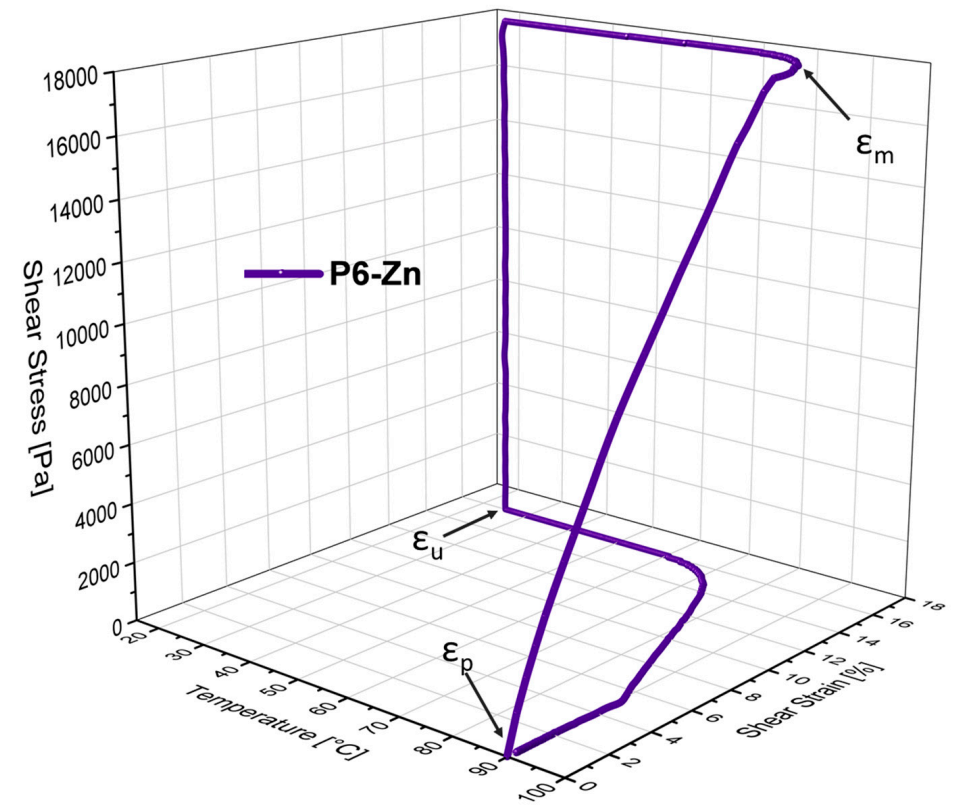

Figure 8. The 3D plot (temperature-stress-strain diagram) of the metallopolymer network P6-Zn.

Table 4. Calculated fixity and recovery rates of the metallopolymer networks P1-Zn, P6-Zn, P7-Zn, P8-Zn and P11-Zn via cyclo-mechanic-tests.

\begin{tabular}{|c|c|c|c|}
\hline Sample & Cycle & $\begin{array}{c}R_{f} \\
{[\%]}\end{array}$ & $\begin{array}{c}R_{r} \\
{[\%]}\end{array}$ \\
\hline \multirow{4}{*}{$\begin{array}{c}\text { P1-Zn } \\
\text { (MMA, 5\% crosslinker, 5\% ligand) }\end{array}$} & 1 & 99.8 & 84.4 \\
\hline & 2 & 100 & 85.5 \\
\hline & 3 & 100 & 81.8 \\
\hline & Average & 99.9 & 83.9 \\
\hline \multirow{4}{*}{$\begin{array}{c}\text { P6-Zn } \\
\text { (EMA, 5\% crosslinker, 5\% ligand) }\end{array}$} & 1 & 98.7 & 95.1 \\
\hline & 2 & 98.7 & 95.0 \\
\hline & 3 & 98.7 & 96.2 \\
\hline & Average & 98.7 & 95.5 \\
\hline \multirow{4}{*}{$\begin{array}{c}\text { P7-Zn } \\
\text { (EMA, 5\% crosslinker, 10\% ligand) }\end{array}$} & 1 & 98.5 & 95.2 \\
\hline & 2 & 98.4 & 95.4 \\
\hline & 3 & 98.4 & 95.4 \\
\hline & Average & 98.4 & 95.3 \\
\hline \multirow{4}{*}{$\begin{array}{c}\text { P8-Zn } \\
\text { (EMA, 5\% crosslinker, 10\% ligand) }\end{array}$} & 1 & 98.5 & 96.3 \\
\hline & 2 & 98.0 & 97.5 \\
\hline & 3 & 98.0 & 98.2 \\
\hline & Average & 98.2 & 97.3 \\
\hline \multirow{4}{*}{$\begin{array}{c}\text { P11-Zn } \\
\text { (BMA, 5\% crosslinker, 5\% ligand) }\end{array}$} & 1 & 99.1 & 96.6 \\
\hline & 2 & 99.1 & 95.8 \\
\hline & 3 & 100.0 & 96.6 \\
\hline & Average & 99.4 & 96.3 \\
\hline
\end{tabular}


Comparing the herein presented system with already existing shape-memory metallopolymers, our fixity rate is in general higher. The 4-oxy-2,6-bis( $N$-methylbenzimidazolyl)pyridine-europium salt system from Kumpfer et al. showed a fixity rate between 87 to 90\% [46]. The triphenylphosphine-Rh system, which also can be found in literature, just was able to fix around $60 \%$ of the deformation [48]. The recovery rates of these polymers were about $90 \%[46,48]$. The herein presented triazole-pyridine-zinc system also shows in general slightly higher values.

To investigate the influence of the formed bis(triazole-pyridine) complex on the shape-memory abilities, also the polymer network P12 (without any metal complex) was pressed at $120{ }^{\circ} \mathrm{C}$ in a rectangular piece and a shape-memory test was performed. The polymer piece was also heated to $90^{\circ} \mathrm{C}$ and deformed. Heating the polymer again to $90^{\circ} \mathrm{C}$ should subsequently trigger the recovery process, but the polymer piece turns very brittle during the recovery step and crumbled in several small pieces (see Figure 9). In opposite to this, the metallopolymer network P12-Zn, which was synthesized from this polymer network even featured triple-shape-memory behavior without losing its transparency or getting crumbly. Figure 9 shows the comparison between P12 and P12-Zn after the shape recovery.

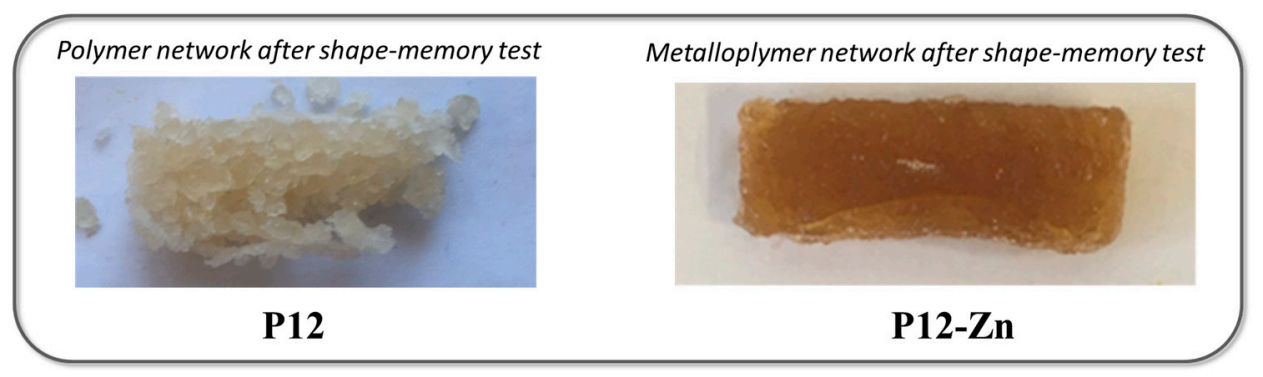

Figure 9. Photos of the polymer networks P12 (left) and the metallopolymer network P12-Zn (right) after the shape-memory test.

\section{Conclusions}

In this work, we showed the successful synthesis of metallopolymer networks featuring a shape-memory effect. The switching unit was obtained by a bis(triazole-pyridine)-metal complex. The polymer networks were synthesized via free radical polymerization and the composition was calculated by elemental analysis and ${ }^{1} \mathrm{H}$ NMR spectroscopy. As metal salt for the formation of the metallopolymer networks zinc(II) and cobalt(II) acetate was chosen, caused by the results of the ITC investigations. The thermal behavior of the polymer and the metallopolymer networks was investigated via DSC and TGA measurements and also the successful complexation in the metallopolymer networks was investigated via FT-IR spectroscopy and exemplarily via ${ }^{1} \mathrm{H}$ NMR spectroscopy. Finally, shape-memory test showed good shape-memory abilities and even the fixation and selective recovery of two different temporary shapes (triple shape-memory) was possible. A performed cyclo-mechanic-test revealed very good fixity (above 98\%) and recovery rates (above 95\%) for all synthesized metallopolymer networks.

Future work will focus on a more detailed investigation of the ongoing molecular processes during the shape recovery process and an analysis of more metal complexes featuring other binding constants. Thus, the impact of the strength of the supramolecular bond on the shape-memory behavior will be analyzed in detail

Supplementary Materials: The following are available online at http://www.mdpi.com/2073-4360/11/11/1889/s1, Figure S1 to S55, Table S1 to S13.

Author Contributions: Synthesis of monomers and polymers: J.M.; DSC, TGA, IR and shape-memory tests: J.M.; Raman measurements: J.H.; ITC-measurements: M.E., rheology measurements: J.V., writing of the manuscript: J.M., interpretation of measurement data: J.M., J.H., S.Z., supervision: S.Z., M.D.H., U.S.S., M.S., J.P.; concept of the study: S.Z., M.D.H., U.S.S., M.S., J.P.; correction of the manuscript: S.Z., M.D.H., U.S.S., M.S., J.P.

Funding: The authors would like to thank the Deutsche Forschungsgemeinschaft (DFG, SCHU 1229/26-1). Furthermore, S.Z. is grateful to the Carl-Zeiss foundation for funding. 
Conflicts of Interest: The authors declare no conflict of interest.

\section{References}

1. Chung, T.; Romo-Uribe, A.; Mather, P.T. Two-way reversible shape memory in a semicrystalline network. Macromolecules 2008, 41, 184-192. [CrossRef]

2. Galaev, I.Y.; Mattiasson, B. 'Smart' polymers and what they could do in biotechnology and medicine. Trends Biotechnol. 1999, 17, 335-340. [CrossRef]

3. Kumar, A.; Srivastava, A.; Galaev, I.Y.; Mattiasson, B. Smart polymers: Physical forms and bioengineering applications. Prog. Polym. Sci. 2007, 32, 1205-1237. [CrossRef]

4. Stuart, M.A.C.; Huck, W.T.S.; Genzer, J.; Müller, M.; Ober, C.; Stamm, M.; Sukhorukov, G.B.; Szleifer, I.; Tsukruk, V.V.; Urban, M.; et al. Emerging applications of stimuli-responsive polymer materials. Nat. Mater. 2010, 9, 101-113. [CrossRef] [PubMed]

5. Schattling, P.; Jochum, F.D.; Theato, P. Multi-stimuli responsive polymers-The all-in-one talents. Polym. Chem. 2014, 5, 25-36. [CrossRef]

6. De Las Heras Alarcon, C.; Pennadam, S.; Alexander, C. Stimuli responsive polymers for biomedical applications. Chem. Soc. Rev. 2005, 34, 276-285. [CrossRef] [PubMed]

7. Chen, G.; Hoffman, A.S. Graft copolymers that exhibit temperature-induced phase transitions over a wide range of pH. Nature 1995, 373, 49-52. [CrossRef]

8. Crespy, D.; Rossi, R.M. Temperature-responsive polymers with LCST in the physiological range and their applications in textiles. Polymer Int. 2007, 56, 1461-1468. [CrossRef]

9. Weber, C.; Hoogenboom, R.; Schubert, U.S. Temperature responsive bio-compatible polymers based on poly(ethylene oxide) and poly(2-oxazoline)s. Prog. Polym. Sci. 2012, 37, 686-714. [CrossRef]

10. Lynn, D.M.; Amiji, M.M.; Langer, R. Ph-responsive polymer microspheres: Rapid release of encapsulated material within the range of intracellular pH. Angew. Chem. Int. Ed. 2001, 40, 1707-1710. [CrossRef]

11. Dai, S.; Ravi, P.; Tam, K.C. Ph-responsive polymers: Synthesis, properties and applications. Soft Matter 2008, 4, 435. [CrossRef]

12. Jochum, F.D.; zur Borg, L.; Roth, P.J.; Theato, P. Thermo- and light-responsive polymers containing photoswitchable azobenzene end groups. Macromolecules 2009, 42, 7854-7862. [CrossRef]

13. Jochum, F.D.; Theato, P. Temperature- and light-responsive smart polymer materials. Chem. Soc. Rev. 2013, 42, 7468-7483. [CrossRef] [PubMed]

14. Tanaka, T.; Nishio, I.; Sun, S.-T.; Ueno-Nishio, S. Collapse of gels in an electric field. Science 1982, $218,467$. [CrossRef]

15. Liu, F.; Urban, M.W. Recent advances and challenges in designing stimuli-responsive polymers. Prog. Polym. Sci. 2010, 35, 3-23. [CrossRef]

16. Dahlke, J.; Zechel, S.; Hager, M.D.; Schubert, U.S. How to design a self-healing polymer: General concepts of dynamic covalent bonds and their application for intrinsic healable materials. Adv. Mater. Interf. 2018, 5, 1800051. [CrossRef]

17. Hu, J.; Liu, S. Responsive polymers for detection and sensing applications: Current status and future developments. Macromolecules 2010, 43, 8315-8330. [CrossRef]

18. Xie, T. Tunable polymer multi-shape memory effect. Nature 2010, 464, 267. [CrossRef]

19. Liu, C.; Qin, H.; Mather, P.T. Review of progress in shape-memory polymers. J. Mater. Chem. 2007, $17,1543$. [CrossRef]

20. Lendlein, A.; Kelch, S. Shape-memory polymers. Angew. Chem. Int. Ed. 2002, 41, 2034-2057. [CrossRef]

21. Behl, M.; Lendlein, A. Shape-memory polymers. Kirk Othmer Encycl. Chem. Technol. 2011, 1-16. [CrossRef]

22. Leng, J.; Lan, X.; Liu, Y.; Du, S. Shape-memory polymers and their composites: Stimulus methods and applications. Prog. Mater. Sci. 2011, 56, 1077-1135. [CrossRef]

23. Hager, M.D.; Bode, S.; Weber, C.; Schubert, U.S. Shape memory polymers: Past, present and future developments. Prog. Polym. Sci. 2015, 49-50,3-33. [CrossRef]

24. Tadaki, T.; Otsuka, K.; Shimizu, K. Shape memory alloys. Annu. Rev. Mater. Sci. 1988, 18, 25-45. [CrossRef]

25. Lendlein, A.; Jiang, H.; Jünger, O.; Langer, R. Light-induced shape-memory polymers. Nature 2005, 434, 879-882. [CrossRef] 
26. Huang, W.M.; Yang, B.; Zhao, Y.; Ding, Z. Thermo-moisture responsive polyurethane shape-memory polymer and composites: A review. J. Mater. Chem. 2010, 20, 3367. [CrossRef]

27. Rivero, G.; Nguyen, L.-T.T.; Hillewaere, X.K.D.; Du Prez, F.E. One-pot thermo-remendable shape memory polyurethanes. Macromolecules 2014, 47, 2010-2018. [CrossRef]

28. Lai, H.-Y.; Wang, H.-Q.; Lai, J.-C.; Li, C.-H. A self-healing and shape memory polymer that functions at body temperature. Molecules 2019, 24, 3224. [CrossRef]

29. Baer, G.; Wilson, T.; Maitland, D.; Matthews, D. 483 shape memory polymer neurovascular stents. J. Invest. Med. 2006, 54, S162. [CrossRef]

30. Santo, L.; Quadrini, F.; Accettura, A.; Villadei, W. Shape memory composites for self-deployable structures in aerospace applications. Proc. Eng. 2014, 88, 42-47. [CrossRef]

31. Wang, X.; Guo, X.; Ye, J.; Zheng, N.; Kohli, P.; Choi, D.; Zhang, Y.; Xie, Z.; Zhang, Q.; Luan, H.; et al. Freestanding 3D mesostructures, functional devices, and shape-programmable systems based on mechanically induced assembly with shape memory polymers. Adv. Mater. 2019, 31, 1805615. [CrossRef]

32. Dalton, E.; Chai, Q.; Shaw, M.W.; McKenzie, T.J.; Mullins, E.S.; Ayres, N. Hydrogel-coated polyurethane/urea shape memory polymer foams. J. Polym. Sci. Part A Polym. Chem. 2019, 57, 1389-1395. [CrossRef]

33. Guo, Y.; Lv, Z.; Huo, Y.; Sun, L.; Chen, S.; Liu, Z.; He, C.; Bi, X.; Fan, X.; You, Z. A biodegradable functional water-responsive shape memory polymer for biomedical applications. J. Mater. Chem. B 2019, 7, 123-132. [CrossRef]

34. Lendlein, A.; Schmidt, A.M.; Schroeter, M.; Langer, R. Shape-memory polymer networks from oligo (є-caprolactone) dimethacrylates. J. Polym. Sci. Part A Polym. Chem. 2005, 43, 1369-1381. [CrossRef]

35. Kim, B.K.; Lee, S.Y.; Xu, M. Polyurethanes having shape memory effects. Polymer 1996, 37, 5781-5793. [CrossRef]

36. Alteheld, A.; Feng, Y.; Kelch, S.; Lendlein, A. Biodegradable, amorphous copolyester-urethane networks having shape-memory properties. Angew. Chem. Int. Ed. 2005, 44, 1188-1192. [CrossRef]

37. Hu, J.; Zhu, Y.; Huang, H.; Lu, J. Recent advances in shape-memory polymers: Structure, mechanism, functionality, modeling and applications. Prog. Polym. Sci. 2012, 37, 1720-1763. [CrossRef]

38. Morshedian, J.; Khonakdar, H.A.; Mehrabzadeh, M.; Eslami, H. Preparation and properties of heat-shrinkable cross-linked low-density polyethylene. Adv. Polym. Tech. 2003, 22, 112-119. [CrossRef]

39. Maksimkin, A.; Kaloshkin, S.; Zadorozhnyy, M.; Tcherdyntsev, V. Comparison of shape memory effect in UHMWPE for bulk and fiber state. J. Alloy. Compd. 2014, 586, S214-S217. [CrossRef]

40. Heuwers, B.; Quitmann, D.; Katzenberg, F.; Tiller, J.C. Stress-induced melting of crystals in natural rubber: A new way to tailor the transition temperature of shape memory polymers. Macromol. Rapid Commun. 2012, 33, 1517-1522. [CrossRef]

41. Burke, K.A.; Mather, P.T. Soft shape memory in main-chain liquid crystalline elastomers. J. Mater. Chem. 2010, 20, 3449. [CrossRef]

42. Xie, T.; Rousseau, I.A. Facile tailoring of thermal transition temperatures of epoxy shape memory polymers. Polymer 2009, 50, 1852-1856. [CrossRef]

43. Yakacki, C.M.; Shandas, R.; Safranski, D.; Ortega, A.M.; Sassaman, K.; Gall, K. Strong, tailored, biocompatible shape-memory polymer networks. Adv. Funct. Mater. 2008, 18, 2428-2435. [CrossRef]

44. Inoue, K.; Yamashiro, M.; Iji, M. Recyclable shape-memory polymer: Poly (lactic acid) crosslinked by a thermoreversible Diels-Alder reaction. J. Appl. Polym. Sci. 2009, 112, 876-885. [CrossRef]

45. Li, J.; Viveros, J.A.; Wrue, M.H.; Anthamatten, M. Shape-memory effects in polymer networks containing reversibly associating side-groups. Adv. Mater. 2007, 19, 2851-2855. [CrossRef]

46. Kumpfer, J.R.; Rowan, S.J. Thermo-, photo-, and chemo-responsive shape-memory properties from photo-cross-linked metallo-supramolecular polymers. J. Am. Chem. Soc. 2011, 133, 12866-12874. [CrossRef] [PubMed]

47. Guan, Y.; Cao, Y.; Peng, Y.; Xu, J.; Chen, A.S.C. Complex of polyelectrolyte network with surfactant as novel shape memory networks. Chem. Commun. 2001, 1694-1695. [CrossRef]

48. Zhang, P.; Behl, M.; Peng, X.; Balk, M.; Lendlein, A. Chemoresponsive shape-memory effect of rhodium-phosphine coordination polymer networks. Chem. Mater. 2019, 31, 5402-5407. [CrossRef]

49. Yang, L.; Zhang, G.; Zheng, N.; Zhao, Q.; Xie, T. A metallosupramolecular shape-memory polymer with gradient thermal plasticity. Angew. Chem. Int. Ed. 2017, 56, 12599-12602. [CrossRef] 
50. Whittell, G.R.; Hager, M.D.; Schubert, U.S.; Manners, I. Functional soft materials from metallopolymers and metallosupramolecular polymers. Nat. Mater. 2011, 10, 176-188. [CrossRef]

51. Happ, B.; Friebe, C.; Winter, A.; Hager, M.D.; Hoogenboom, R.; Schubert, U.S. 2-(1 H-1,2,3-Triazol-4-yl)-pyridine ligands as alternatives to 2,2'-bipyridines in ruthenium(II) complexes. Chem. Asian J. 2009, 4, 154-163. [CrossRef] [PubMed]

52. Happ, B.; Pavlov, G.M.; Perevyazko, I.; Hager, M.D.; Winter, A.; Schubert, U.S. Induced charge effect by co(II) complexation on the conformation of a copolymer containing a bidentate 2-(1,2,3-Triazol-4-yl)pyridine chelating unit. Macromol. Chem. Phys. 2012, 213, 1339-1348. [CrossRef]

53. Hannewald, N.; Enke, M.; Nischang, I.; Zechel, S.; Hager, M.D.; Schubert, U.S. Mechanical activation of terpyridine metal complexes in polymers. J. Inorgan. Organometall. Polym. Mater. 2019, 1-13. [CrossRef]

54. Fleischhaker, F.; Haehnel, A.P.; Misske, A.M.; Blanchot, M.; Haremza, S.; Barner-Kowollik, C. Glass-transition-, melting-, and decomposition temperatures of tailored polyacrylates and polymethacrylates: General trends and structure-property relationships. Macromol. Chem. Phys. 2014, 215, 1192-1200. [CrossRef]

55. Denissen, W.; Winne, J.M.; Du Prez, F.E. Vitrimers: Permanent organic networks with glass-like fluidity. Chem. Sci. 2016, 7, 30-38. [CrossRef]

56. Mozhdehi, D.; Neal, J.A.; Grindy, S.C.; Cordeau, Y.; Ayala, S.; Holten-Andersen, N.; Guan, Z. Tuning dynamic mechanical response in metallopolymer networks through simultaneous control of structural and temporal properties of the networks. Macromolecules 2016, 49, 6310-6321. [CrossRef]

(C) 2019 by the authors. Licensee MDPI, Basel, Switzerland. This article is an open access article distributed under the terms and conditions of the Creative Commons Attribution (CC BY) license (http://creativecommons.org/licenses/by/4.0/). 